\title{
CONDIÇÕES HIDROGEOLÓGICAS DOS AQÜÍFEROS ARTESIANOS NA REGIÃO DO COMPLEXO PETROQUÍMICO DE CAMAÇARI, BAHIA
}

\author{
OLIVAR A.L. DE LIMA* e TELMA A.D. MIRANDA**
}

\begin{abstract}
HYDROGEOLOGICAL CONDITIONS OF THE ARTESIAN AQUIFERS IN CAMACCARI PETROCHEMICAL COMPLEX REGION, BAHIA. The upper portion of the São Sebastião Formation, in the Recôncavo Basin, Bahia, is a multi-layered artesian aquifer system composed of alternating sandstones and shales, with a thickness greater than 1,000 m. Electrical logs of 95 wells for both oil and water exploration in the region of the Camaçari Petrochemical pole have been studied with the aim of defining the structural configuration and the petrophysical characterization of the main sandstones bodies tapped by the wells. The geometry and internal structures of theses bodies, as clearly displayed in the SP and resistivity curves, suggest that they originated as point bar sands of a large fluvial environment. The water quality determined by chemical analysis and inferred from the logs is related to the general pattern of flow, the salt content being modified both by cation exhange within disseminated clays and by ionic filtering through confining shales. A thermal anomaly contour map constructed from borehole temperature data reveals a regional pattern of water transfer between sandstones by means of vertical leakages through the shale layers. Temperatures logs performed in nine water wells were used to estimate the rates of this leakage, which is in the order of $8.4 \times 10^{-7}$ to $1.2 \times 10^{-6} \mathrm{~cm} / \mathrm{s}$. Combined piezometric and pumping data of the Camaçari well field attest clearly to the highly severe exploitation the aquifer is undergoing in this region. Considering the high level of surface water contamination by industrial and oil exploratory activities in the area, these data suggest an imminent risk of polution for this important groundwater reserve and calls for a rigorous control by government agencies.
\end{abstract}

INTRODUÇÃo A Formação São Sebastião nas bacias do Recôncavo e Tucano, Bahia, compreende uma seqüência de arenitos, folhelhos e siltitos do Cretáceo Inferior, com mais de $1.000 \mathrm{~m}$ de espessura. Ela contém um dos mais importantes sistemas aqǘfferos do Estado em termos de reservas, qualidade da água e produtidade de poços (Leite 1964). Grande parate do suprimento de água do Complexo Petroquímico de Camaçari (Copec), do Centro Industrial de Aratu (CIA) e das populaçōes de várias cidades e vilas da região (Fig. 1) é obtida desse sistema através de poços tubulares profundos. $\mathrm{Na}$ área do Copec, estima-se que a água subterrânea atenda a mais de $60 \%$ do consumo industrial (URPLAN 1985).

Embora extensa e intensivamente explorados, esses aqüfferos carecem de estudos detalhados sobre sua hidrologia subterrânea, especialmemte no que diz respeito à geometria e às propriedades hidráulicas dos corpos de arenitos, à influência hidrodinâmica de uma densa tectônica de falhamento e às características químicas da água. Além disso, a intensa atividade industrial petroquímica instalada no Copec, onde operam mais de 50 empresas do setor, bem como a atividade de extração de petróleo em diversos campos da área (Fig. 1) têm sido responsáveis por uma poluição crescente dos cursos de água superficial e representam riscos iminentes de contaminação da água subterrânea armazenada nesse sistema aqǘfero.

Alguns estudos hidrogeologicos conduzidos em áreas de ocorrência da Formação São Sebastião (Lima \& Ribeiro 1982, Oliveira \& Lima 1986) têm mostrado que esta formação corresponde a uma sucessão vertical de camadas e lentes de arenitos e de folhelhos interestratificados, que é freqüentemente seccionada por sistemas escalonados de falhas gravitacionais. Tais estudo evidenciaram também a presença de variaçōes de qualidade da água entre diferentes níveis arenosos, assim co-

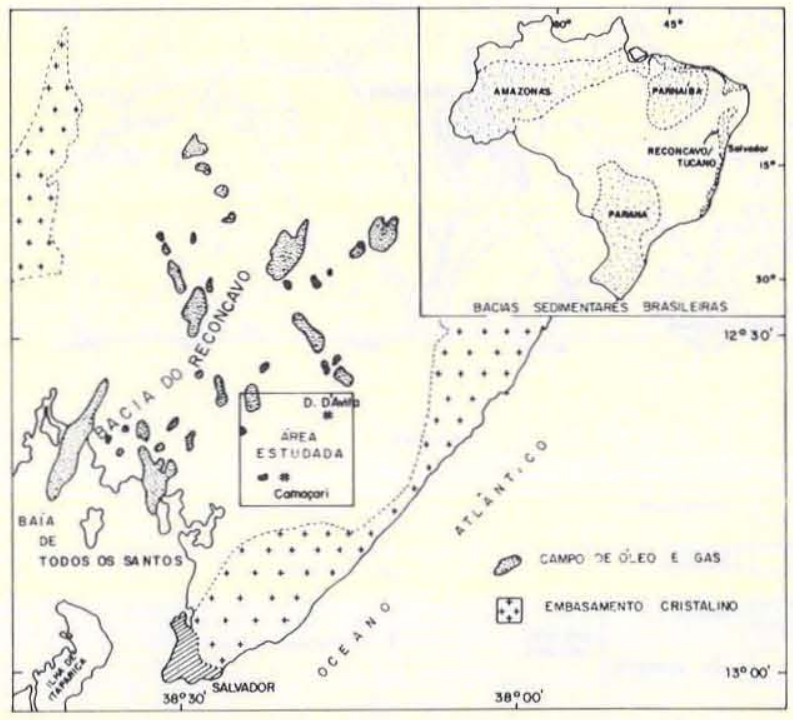

Figura 1 - Mapa da situação da área estudada

mo levantaram a possibilidade da interconexão hidráulica do fluxo entre os vários arenitos, tanto verticalmente, através de folhetos semipermeáveis, como lateralmente, através de superfícies ou zonas de falhamentos.

No presente trabalho, foram analisados perfis elétricos de 95 poços da região de Camaçari (Fig. 2), perfurados em conexẫo com a exploração de petróleo e de água subterrânea, com o fim de se obter uma avaliação hidrogeológica do sistema aqüffero São Sebastião nessa região, em termos da geometria tridimensional e das propriedades petrofísicas dos cor-

* Programa de Pesquisa e Pós-Graduação em Geoffsica, Instituto de Geociências, UFBA. Rua Caetano Moura, 123, Campus da Federação, CEP 40210, Salvador, BA, Brasil

** Instituto de Física, UFBA, Rua Caetano Moura, 123, Campus da Federaçåo, CEP 40210, Salvador, BA, Brasil 
pos de arenitos que ocorrem até cerca de $300 \mathrm{~m}$ de profundidade, que corresponde à média da penetração dos poços. Alêm disso, foram estudados nove perfis de temperatura executados em alguns dos poços exploratórios de água objetivando determinar taxas de filtração vertical da água através dos folhetos semiconfinantes, assim com estimar outros padrões da circulação subterrânea usando as pertubações que o bombeamento em poços vizinhos provocam nos gradientes geotérmi$\cos$ naturais. Combinando os dados piezométricos e da vazão dos poços em diferentes épocas com as análises físico-químicas das águas, tentou-se também caracterizar o nível de exploração desses aqüfferos bem como avaliar sua vulnerabilidade à poluição, já detectada em superfície e causada pela intensa atividade industrial.

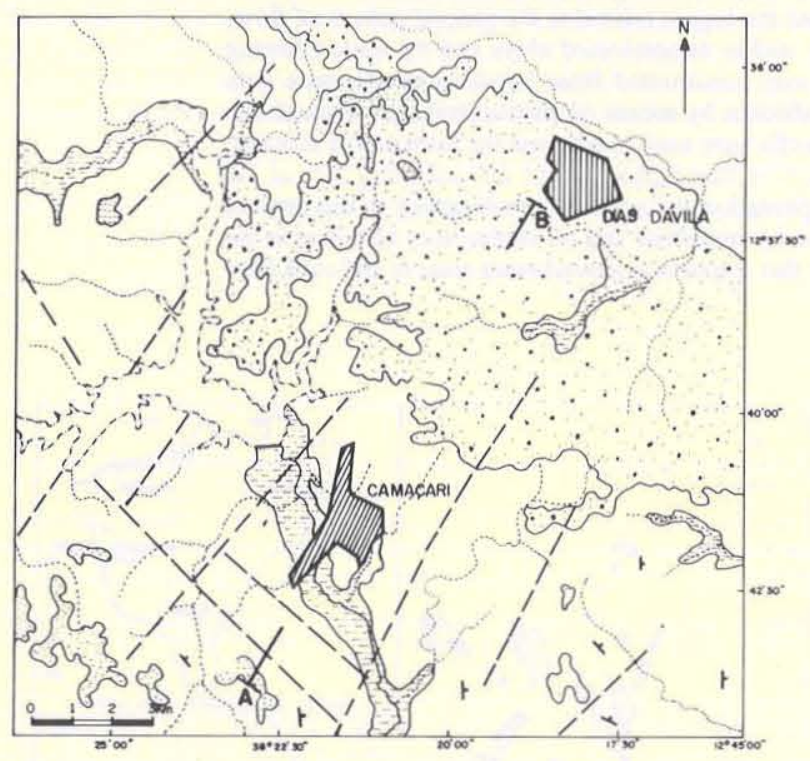

LEOENDA

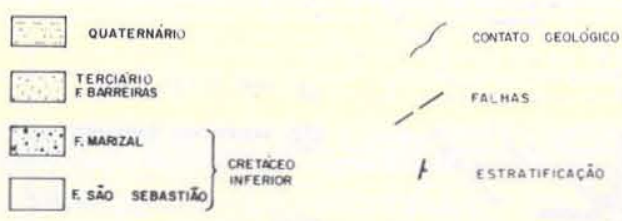

Figura 2 - Mapa geologico da área estudada

SITUAÇÃO GEOLÓGICA A bacia sedimentar do Recôncavo faz parte do sistema de bacias eocretáceas do leste brasileiro, cuja origem e evolução estão diretamente relacionadas à separação entre os continentes africano e sul-americano (Asmus \& Porto 1972, Milani 1986). Trata-se de uma fossa tectônica implantada sobre rochas pré-cambrianas do Cráton de São Francisco e preenchida por sedimentos continentais flúvio-lacustre, desde o Neojurássico. Esses sedimentos constituem o chamado Supergrupo Bahia, cuja espessura máxima atinge cerca de $6.000 \mathrm{~m}$ (Viana et al. 1971).

O supergrupo Bahia compreende, assim, uma espessa seqüência de folhelhos, arenitos e calcários, da qual faz parte a Formação São Sebastião, objeto específico desse trabalho. $\mathrm{Na}$ região estudada, ela está parcialmente recoberta pelos sedimentos das formaçōes Marizal e Barreiras. Estratigraficamente, a Formação Marizal sobrepőe-se em discordância angular à formação São Sebastião e está sotoposta, em discordância paralela, à Formação Barreiras (Fig. 2).

A Formação São Sebastião, do Eocretáceo, é contituída por intercalações de espessos bancos de arenitos de cor e granulação variadas, e de camadas e lentes de folhelhos e siltitos. Sua espessura no Recôncavo varia de 30 a 2.800 m, com at€ $1.000 \mathrm{~m}$ de sedimentos saturados de água doce (Leite 1964).

A Formação Marizal, também do Eocretáceo, é caracte'rizada por um conglomerado basal e por arenitos variegados, com espessura não maior que $30 \mathrm{~m}$. Já a Formação Barreiras constitui uma seqüência continental do Terciário, também com cerca de 30 a $40 \mathrm{~m}$ de espessura, composta predominantemente de arenitos. Por causa de suas disposições topográficas nas partes mais elevadas do terreno e por suas pequenas espessuras, essas duas formações não constituem aqǘfferos importantes na região.

Sedimentos de distribuição mais restrita constituem os depósitos aluviais do Quartenário, de reduzida espessura, que preenchem os vales e as baixadas.

As principais feiçőes estruturais da área são os sistemas de falhamentos sin e pósdeposicionais, que seccionaram o pacote sedimentar da bacia em conjunto de blocos com um alinhamento estrutural preferencial de direção NNE. A direção de falhamentos mais freqüente é N20-30E, correspondendo a um conjunto de falhas gravitacionais paralelas à direção do substrato da fossa e que constituem limites laterais de altos e baixos estruturais. Um outro conjunto de falhas, com direção $\mathrm{N} 30-40 \mathrm{~W}$, possui componentes direcionais de deslocamento refletindo o padrão de esforços distensivos da separação continental (Milani 1986).

Uma outra feição estrutural importante na área estudada é a de um amplo antiformal, com fechamento localizado a SW de Camaçari e de direção axial N20E, no qual as camadas da Formação São Sebastião estão arqueadas até a $30^{\circ}$ de mergulho (Fig. 2).

\section{CARACTERÍSTICAS GEOMÉTRICAS E PETROFÍSICAS DOS ARENITOS A figura 3 contém o perfil geo-elétrico} composto do poço RJST-1-BA, incluindo os padrões de variaçöes de alguns parâmetros petrofísicos dos arenitos, determinados em testemunhos de sondagem. A figura ilustra, de maneira significativa, o comportamento geofísico da Formação São Sebastião na área estudada. As deflexōes nas curvas de SP e de restividade elêtrica permitem definir com segurança os limites das camadas, assim com refletem algumas importantes feições litologicas dos arenitos, confirmadas pelas informações extraídas da análise dos testemunhos, conforme será discutido adiante.

A figura 4 representa um perfil vertical de correlação litoestratigráfica orientado transversalmente à estrutura geol6gica da área, mostrando a presença de vários níveis espessos de arenitos, separados por camadas ou lentes de folhelhos e truncados por falhamentos gravitacionais.

Esses corpos areníticos possuem cores variando de cinza a róseos e amarelados, e granulação variando de fina a média, com ocorrências locais de grânulos e seixłos de quartzo. Observa-se em todos eles um padrão ascendente de granodecrescência e de aumento da argilosidade, bem caracterizados no perfil de diâmetro médio dos grãos (Fig. 3) e refletidos nas curvas de SP e resistividade. Eles variam ainda de estratificados a maciços, apresentam-se pouco consolidados, com grãos 


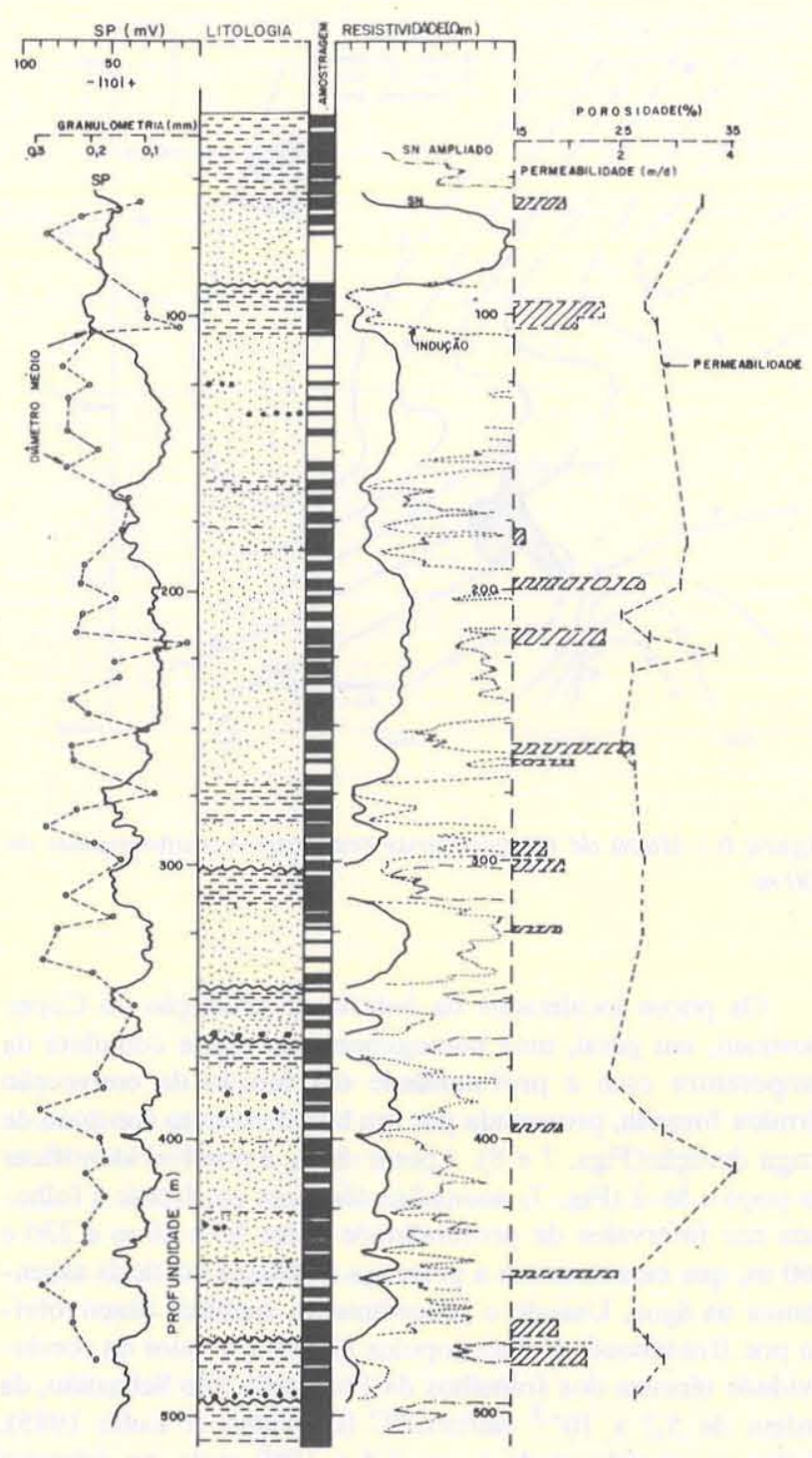

Figura 3 - Perfil geofísico composto do poço RJST-1-BA subarredondados e arredondados, regularmente a bem classificados e com baixo teor de minerais de argila na matriz, exceto em seus topos. A estratificação dominante é do tipo cruzada, passando a paralela nas partes superiores da seqüências. As feições geométricas dos perfis elétricos em frente aos arenitos revelam a presença de contatos abruptos na base, sugerindo erosão, e um desenvolvimento gradacional para folhetos no topo de cada nível. Cerca de 40 amostras de testemunhos extraídos no poço RJST-1-BA, representativas desses arenitos, forneceram valores de porosidade entre $24,6 \%$ e $32,7 \%$ e de permeabilidade intrínseca no intervalo de 190 a $5.700 \mathrm{mD}$. Os valores médios dessas propriedades no conjunto das amostras são de $27,5 \%$ e $1.870 \mathrm{mD}$, com desvios-padrão de 1,88 e 780 , respectivamente.

Os folhetos e siltitos associados são de cores variadas, predominando os cinza-esverdeados e avermelhados, em alguns poços ocorrendo folhelhos marrons e arroxeados. Os intervalos mais espessos são normalmente contínuos através da área, muito deles, porém, representando corpos lenticulares de pequena extensão lateral. Todos eles são normalmente micáceos e parcialmente calćfferos. A heterogeneidade composicional revelada por variações de granulometria e de cor dessas litologias é refletida por um comportamento irregular da resistividade elétrica em frente a essas camadas.

A figura 5 mostra o mapa de isópacas de arenitos nos $200 \mathrm{~m}$ superiores da Formação São Sebastiâo, contruído com base nos dados de todos os poços com perfis elétricos disponíveis. Verifica-se um padrão de distribuição ligeiramente sigmoidal, com orientação geral NE e com o desenvolvimento das maiores espessuras no setor nordeste da área estudada. Esse padrão parece também ser mantido em maiores intervalos de profundidade (ate $500 \mathrm{~m}$ ), embora o pequeno número de dados não tenha permitido uma representação em mapa.

As feições estratigráficas refletidas nos perfis elétricos dos poços e a distribuição espacial dos arenitos indicada na figura 5 são consistentes com uma origem fluvial para a Formação São Sebastião, conforme interpretam vários autores (Viana et al. 1971, Lima \& Ribeiro 1982). Os arenitos correspondem às areias de barras de pontais de correntes meandrantes e os folhelhos representam os depósitos de planície de inundação e/ou de preenchimento de canais de meandros abandona-

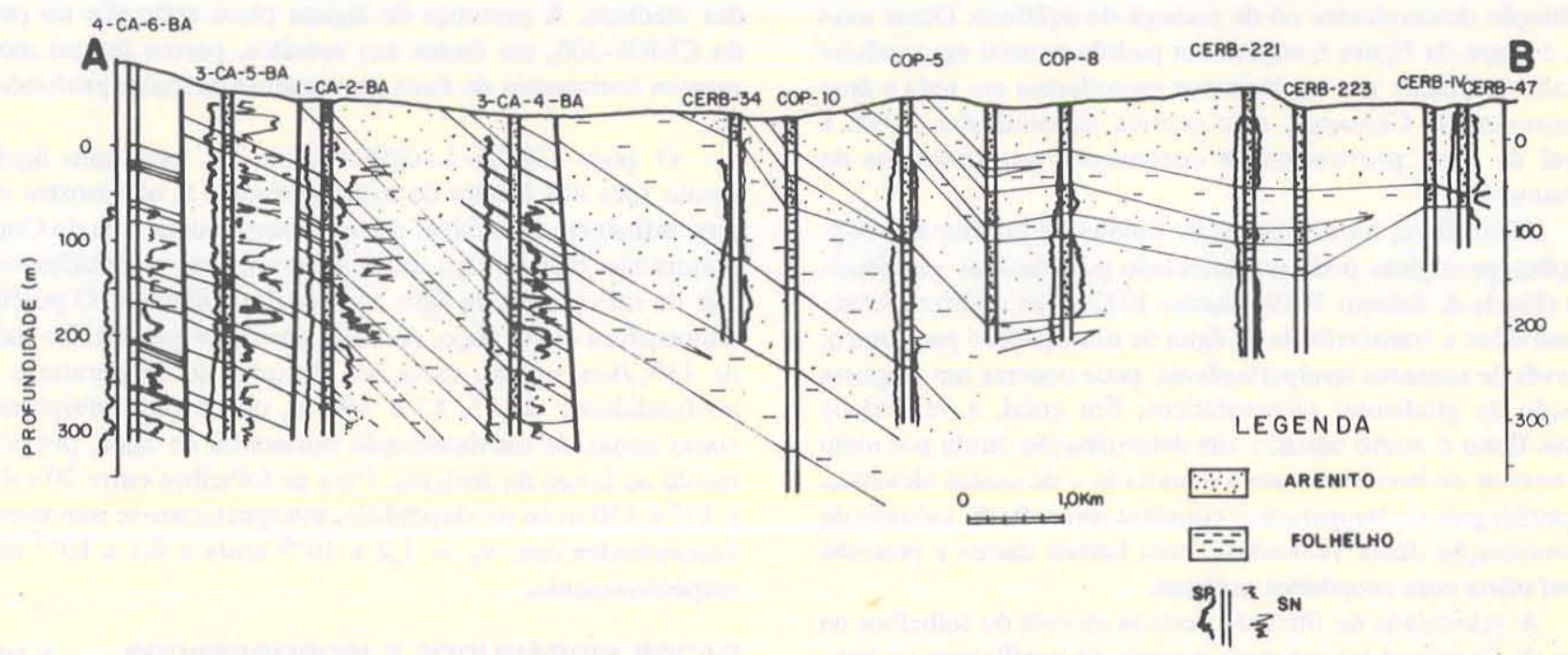

Figura 4 - Seção geologico-estrutural transversal d̀ direção das camadas 


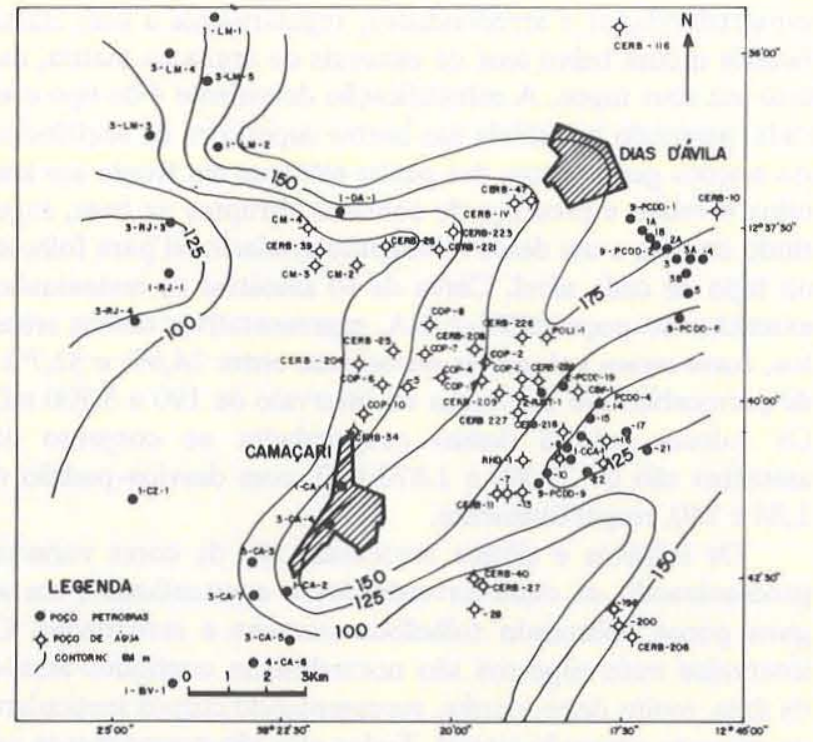

Figura 5 - Mapa de isópacas de arenitos acima de $200 \mathrm{~m}$ de profundidade

dos, em conformidade com os modelos definidos por Visher (1965) e Allen (1975)

\section{DADOS GEOTÉRMICOS Para avaliar a possibili-} dade de detectar o lento movimento regional da água subterrânea por meios termológicos foi contruído um mapa residual de temperaturas na profundidade de $500 \mathrm{~m}$, a partir de temperaturas de fundo, medidas em poços de exploração de petróleo, e dos gradientes médios, medidos em poços de extração de água subterrânea. Os valores residuais na profundidade referida foram calculados pela diferença entre o valor linearmente interpolado em cada poço e o valor calculado com base no gradiente geotérmico médio, computado a partir do conjunto de todos os dados de temperatura e de profundidade. No mapa residual assim construído (Fig. 6), considera-se que as áreas mais quentes (positivas) representam zonas de movimentação natural ascendentes de água a partir dos aqǘferos mais profundos e, as áreas frias (negativas), zonas de movimentação descendentes ou de recarga do aqüffero. Desse modo, o mapa da figura 6 sugere um padrão natural em profundidade dominado por movimentos ascendentes em toda a área a noroeste de Camaçari, com centros descendentes a NE e a sul da área, provavelmente controlados por conjuntos de falhamentos.

Alem disso, o movimento de fluidos no interior das formações geologicas pode ser detectado por medidas geotérmicas (Boyle \& Saleem 1979, Hamza 1982). Em aqüíferos multiacamados a transferência de água de um aqüffero para outro, através de camadas semipermeáveis, pode ocorrer um resposta à ação de gradientes piezométricos. Em geral, a velocidade desse fluxo é muito baixa, e sua determinação direta por meio de ensaios de bombeamento $\varepsilon$ demorada e de custos elevados. A perfilagem de temperatura constitui um método indireto de determinação dessa velocidade, com baixos custos e precisão satisfatória para propósitos práticos.

A velocidade de filtração vertical através do folhelhos na área de Camaçari foi estimada a partir de perfilagens de temperatura realizadas em nove poços de extração de água acessiveis na área, com profundidades entre 200 e $300 \mathrm{~m}$.

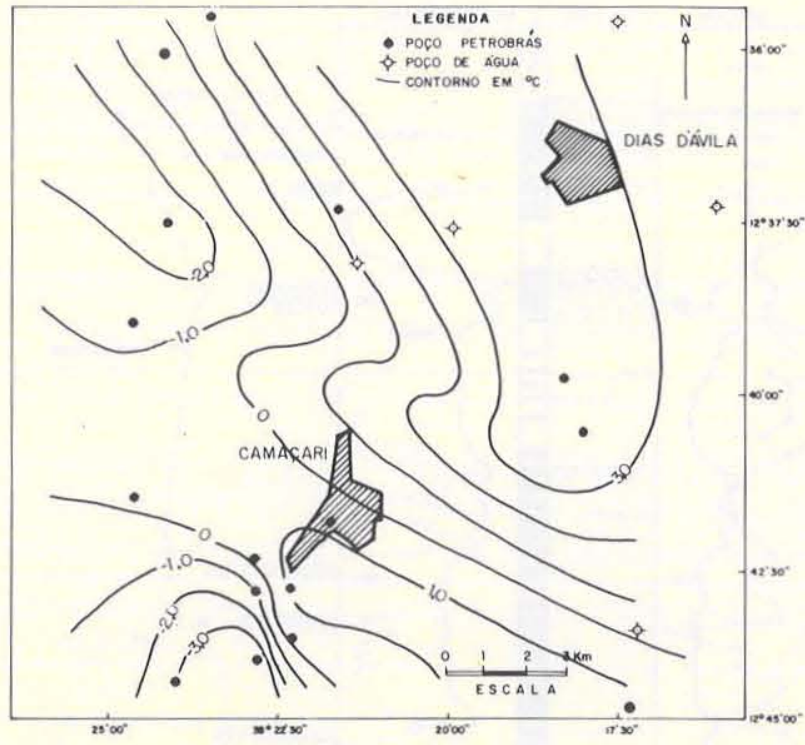

Figura 6 - Mapa de temperaturas residuais à profundidade de $500 \mathrm{~m}$

Os poços localizados na bateria de produção do Copec mostram, em geral, uma homogeneização quase completa da temperatura com a profundidade em função da convecção térmica forçada, provocada por um bombeamento contínuo de longa duração(Figs. 7 e 8). Apesar disso, é possível identificar no poço CM-2 (Fig. 7) anomalias térmicas em frente a folhelhos nos intervalos de profundidade entre 50 e $80 \mathrm{~m}$ e 230 e $260 \mathrm{~m}$, que caracterizam a presença de fluxos verticais ascendentes da água. Usando o procedimento analítico desenvolvido por Bredehoeft \& Papadopulos (1965) e o valor da condutividade térmica dos folhelhos da Formação São Sebastião, da ordem de $5,2 \times 10^{-3} \mathrm{cal} / \mathrm{cm} \cdot \mathrm{s}^{\circ} \mathrm{C}$ (Carvalho \& Lobo 1985), obtém-se os valores de $\mathrm{v}_{\mathrm{Z}}=2,4 \times 10^{-6} \mathrm{~cm} / \mathrm{s}$, no primeiro intervalo, e de $\mathrm{v}_{\mathrm{z}}=8,4 \times 10^{-7} \mathrm{~cm} / \mathrm{s}$, no segundo.

Os poços CERB-200 e CERB-206, situados ligeiramente fora da bateria do Copec, mostram ainda efeitos de homogeneização da temperatura, em função do bombeamento no poço vizinho CERB-198, durante o período de realização das medidas. A presença de alguns picos anômalos no perfil do CERB-206, em frente aos arenitos, parece indicar movimentos horizontais de água proveniente de maior profundidade.

O poço CERB-1.1089/80 (Fig. 8), localizado ligeiramente fora dos limites do mapa da figura 5 , não mostra mais uma influência apreciável do bombeamento na área do Copec, permitindo estimar com maior segurança as velocidades verticais do movimento da água através dos folhelhos. O perfil de temperatura desse poço, com um gradiente geotérmico médio de $11^{\circ} \mathrm{C} / \mathrm{km}$, mostra variaçöes abruptas de temperaturas nas profundidades de 55,85 e $160 \mathrm{~m}$, que foram interpretadas como zonas de movimentação horizontal de água, provavelmente ao longo de fraturas. Para os folhelhos entre 20 e $47 \mathrm{~m}$ e 135 e $150 \mathrm{~m}$ de produndidade, interpretaram-se movimentos descendentes com $\mathrm{v}_{\mathrm{z}}=1,2 \times 10^{-6} \mathrm{~cm} / \mathrm{s}$ e $6,1 \times 10^{-7} \mathrm{~cm} / \mathrm{s}$, respectivamente.

DADOS HIDRÁULICOS E HIDROQUÍMICOS A tabela 1 contém resultados de análises físico-químicas de amostras de água coletadas nos poços do Copec, fornecidas aos autores 


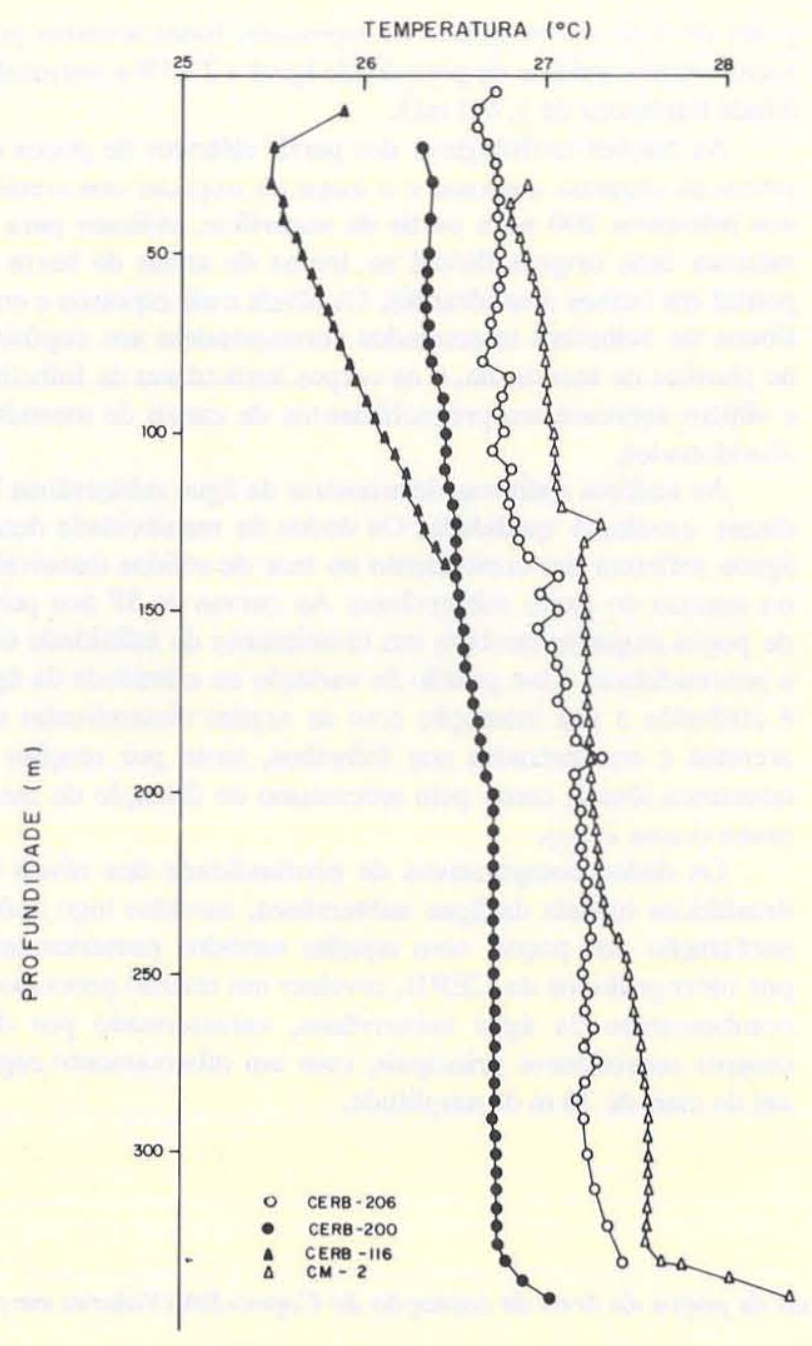

Figura 7 - Perfis de temperatura em poços da área de Camaçari

pela Companhia de Engenharia Rural da Bahia (CERB). São águas cloretadas, com baixos teores de sais dissolvidos, excelentes para consumo humano. Suas resistividades elétricas são elevadas, normalmente acima de $50 \mathrm{ohm} . \mathrm{m}$, a $25^{\circ} \mathrm{C}$. Essa propriedade, lançada em mapa (Fig. 9), apresenta uma diminuição sensivel de valor no sentido geral do fluxo subterrâneo, indicando um crescimento de salinidade com a distância. Obviamente, a água coletada nos poços representa uma mistura das águas provenientes dos diferentes níveis arenosos. Todavia, a maioria dos perfis elétricos dos poços (Figs. 3 e 4) contém curvas de potencial espontâneo que mostram claramente um decréscimo na deflexão do SP em relação à linha dos folhelhos, com o aumento da profundidade dos arenitos. Embora sem dispor dos dados relativos à lama de circulação, é possível interpretar qualitativamente essas variaçöes de SP em termos de aumentos da salinidade da água com a profundidade.

Como forma de avaliar o grau de exploração aplicado ao sistema aqüiffero em função da atividade do Copec, foram confeccionados os mapas das figura 10 usando as medidas de nível piezométrico obtidas imediatamente após a penfuração dos poços, bem como durante um levantamento sistemático de inventário hidrogeológico realizado em 1982 pelo Estado (CERB 1982, comunicação pessoal). Em lin has cheias estão indicados os contornos de profundidade da água, contruídos

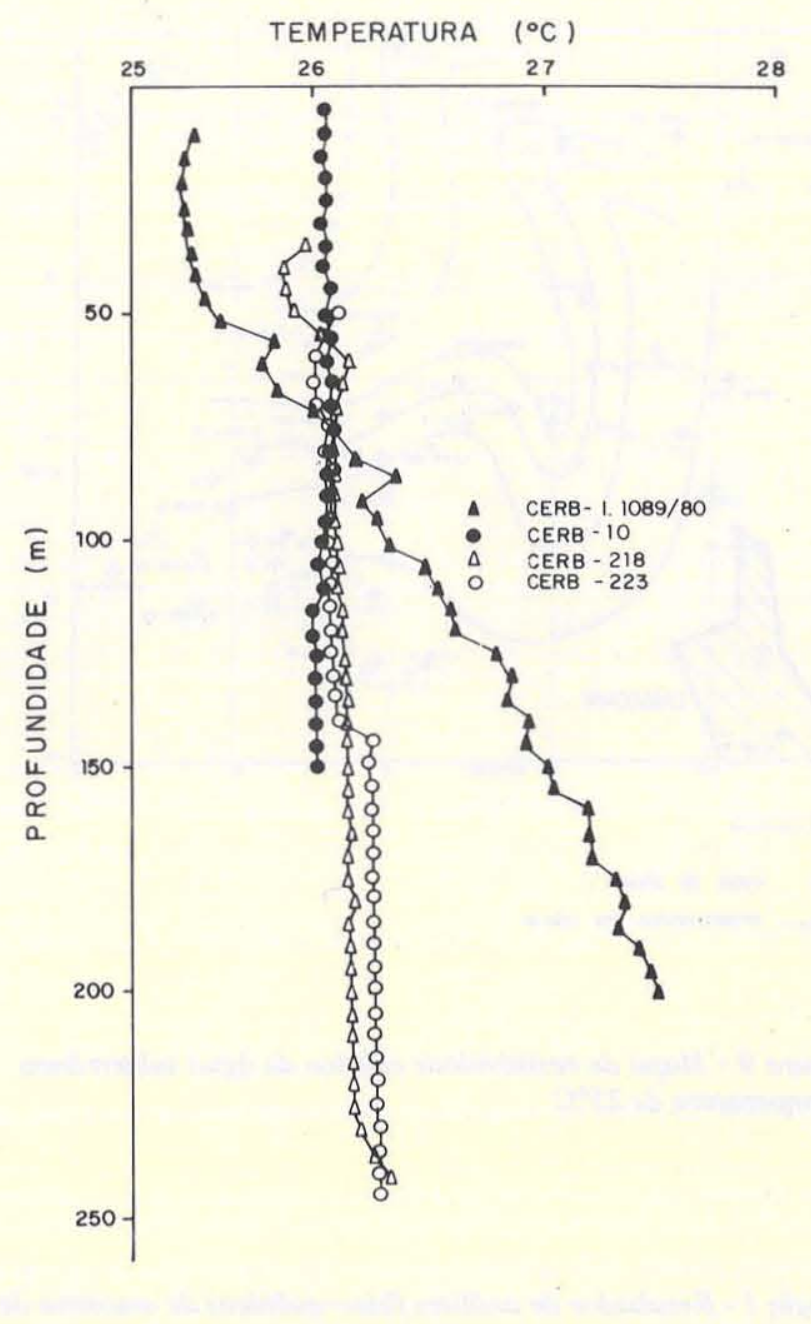

Figura 8 - Perfis de temperatura em poços da área de Camaçari

com base nos dados obtidos durante a perfuração dos poços, antes de 1979, ano em que se intensificou a exploração do aqüífero pelo Copec. Esses contornos indicam um padrão geral de fluxo subterrâneo divergente a partir de uma faixa que contém os poços CERB-202 e CERB-10, e que atua como divisor de água no aqüífero, estendendo-se lateralmente em direção à rede de drenagem superficial.

As linhas pontilhadas indicam os contornos de profundidade obitdos no cadastramento de 1982, quando vários poços se encontravam em franca produção. Trata-se, portanto, de um representação dinâmica da distribuição dos níveis de água nos poços. A figura 10 mostra a existência de dois centros sorvedouros acentuados de água do sistema, nos quais uma apreciável depressão dos níveis piezométricos vem sendo induzida pelo bombeamento. Essa ampla depressão do potencial piezométrico nos aqǘferos artesianos mais profundos induz uma inversão no fluxo vertical através das camadas semipermeáveis, favorecendo uma maior infilltração de água a partir dos níveis mais superficiais, em parte já contaminada pela atividade industrial.

DISCUSSÃO E CONCLUSÕES O sistema aqüffero São Sebastião na região do Copec, Bahia, compreende uma seqüência de arenitos e folhelhos com uma proporção aproxi- 


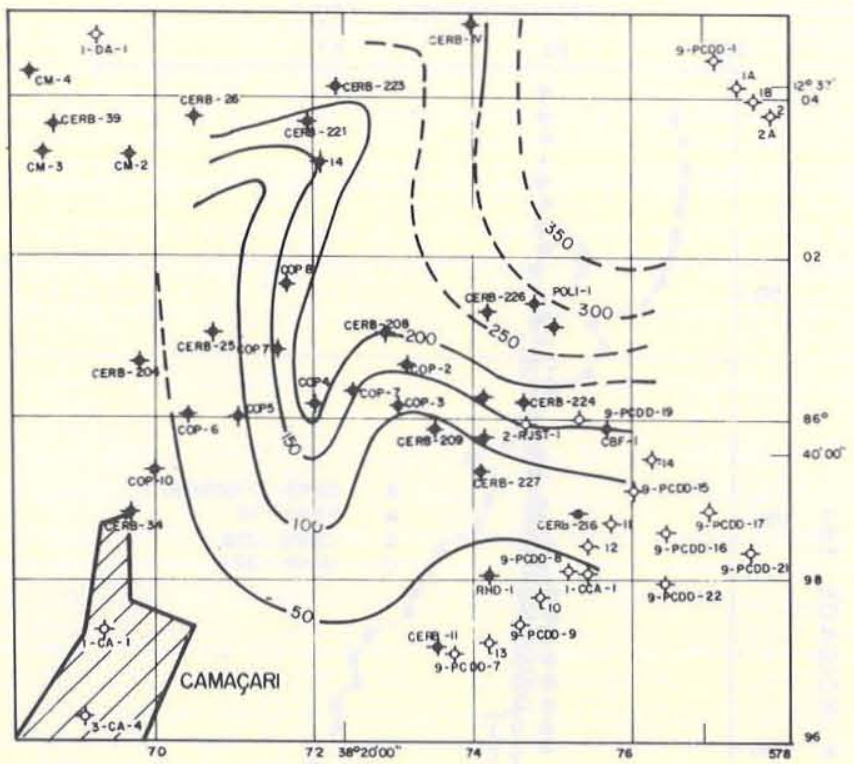

LEGENDA

- POGO DE AGUA

- 100 - RESISTIVIDADE EM O Omm.m

Figura 9 - Mapa de resistividade elétrica da água subterrânea à temperatura de $25^{\circ} \mathrm{C}$ mada de 3-6: 1, em termos de espessura. Esses arenitos possuem valores médios de porosidade igual a $27,5 \%$ e permeabilidade intrínseca de $1.780 \mathrm{mD}$.

As feições mofológicas dos perfis elétricos de poços em frente às camadas arenosas e o mapa de isopacas dos arenitos nos primeiros $200 \mathrm{~m}$, a partir da superfície, indicam para os mesmos uma origem fluvial na forma de areias de barra de pontal em cursos meandrantes. Os níveis mais espessos e contínuos de folhelhos intercalados correspondem aos depositos de planície de inundação, e os corpos lenticulares de folhelhos e siltitos representam preenchimentos de canais de meandros abandonados.

As análises químicas de amostras da água subterrânea indicam excelente qualidade. Os dados de resistividade dessas águas refletem um crescimento no teor de sólidos dissolvidos no sentido do fluxo subterrâneo. As curvas de SP nos perfis de poços sugerem também um crescimento da salinidade com a profundidade. Esse padrão de variação na salinidade da água E atribuído a sua interação com as argilas disseminadas nos arenitos e concentradas nos folhelhos, tanto por reações de intertroca iônica, como pelo mecanismo de filtração de membrana (Lima 1983).

Os dados comparativos de profundidade dos níveis hidrostáticos iniciais da água subterrânea, medidos logo após a perfuração dos poços, com aqueles medidos posteriormente por hidrogélogos da CERB, revelam um intenso processo de bombeamento da água subterrânea, caracterizado por dois centros sorvedouros principais, com um rebaixamento regional de mais de $30 \mathrm{~m}$ de amplitude.

Tabela 1 - Resultados de análises fisico-químicas de amostras de água de poços da área de captação do Copec-BA (Valores em ppm)

\begin{tabular}{l|c|c|c|c|r|r|r|r}
\hline Poģo & $\mathrm{Ca}^{++}$ & $\mathrm{Mg}^{++}$ & $\mathrm{Na}^{+}$ & $\mathrm{K}^{+}$ & $\mathrm{Cl}^{-}$ & $\mathrm{HCO}_{3}^{--}$ & $\mathrm{pH}$ & $\mathrm{R}(\mathrm{ohm} . \mathrm{m})$ \\
\hline CERB-26 & 0,4 & 0,485 & 4,9 & 10,0 & 11,0 & 8,0 & 4,8 & - \\
CERB-40 & 0,6 & 1,2 & 8,2 & 8,0 & 10,0 & 24,0 & 6,4 & 135,1 \\
CERB-47 & 0,4 & 0,7 & 3,8 & 0,3 & 8,0 & 1,2 & 4,9 & 357,1 \\
CERB-117 & 58,0 & 2,18 & - & - & 13,5 & 57,5 & 7,8 & 65,8 \\
CERB-208 & 0,05 & - & - & - & 10,0 & - & 6,7 & 204,1 \\
COP-06 & 9,2 & 11,9 & 16,0 & 10,9 & 16,0 & 56,0 & 6,9 & 54,6 \\
COP-05 & 4,0 & 6,54 & 11,7 & 6,0 & 17,0 & 26,0 & 6,2 & 80,6 \\
CERB-800 & 0,9 & 2,4 & 5,5 & 12,3 & 10,0 & 27,0 & 7,2 & 106,4 \\
CERB-811 & 2,0 & 1,46 & - & - & 6,0 & 2,0 & 5,9 & 285,7 \\
CERB-812 & 0,4 & 0,72 & 4,1 & 0,4 & 9,0 & 3,6 & 5,0 & 290,7 \\
CERB-813 & 2,0 & 0,73 & 0,2 & 0,06 & 6,5 & 4,0 & 7,0 & 147,5 \\
CERB-216 & 5,0 & 3,89 & 0,50 & 0,18 & 21,0 & 20,0 & 7,5 & 80,0 \\
CERB-217 & 3,0 & 4,0 & 4,9 & - & 9,0 & 6,0 & 6,2 & 227,0 \\
COP-01 & 1,0 & 4,0 & - & - & 9,0 & 6,8 & 5,5 & - \\
COP-02 & 2,0 & 4,0 & 5,2 & 3,8 & 11,0 & 7,2 & 5,9 & 188,7 \\
COP-03 & 2,0 & 3,05 & 8,4 & 4,3 & 17,0 & 10,6 & 5,8 & 122,0 \\
COP-04 & 2,0 & 2,26 & 8,0 & 6,5 & 15,0 & 14,0 & 5,9 & 222,2 \\
COP-07 & 2,0 & 3,0 & 6,4 & 2,8 & 10,0 & 7,6 & 5,8 & 142,9 \\
\hline
\end{tabular}




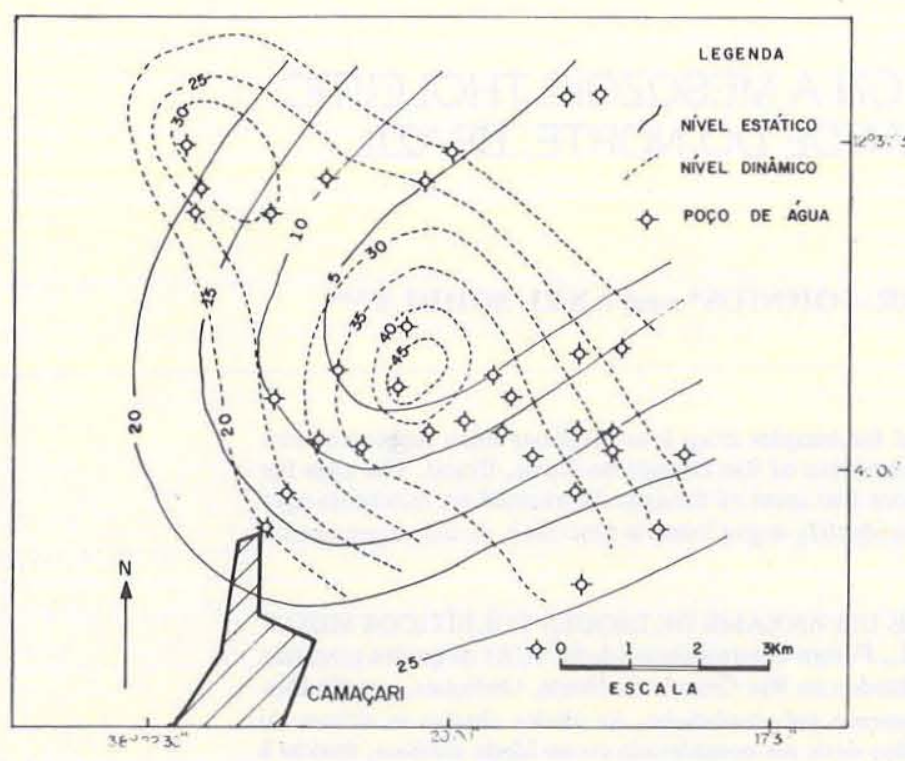

Figura 10 - Mapa de profundidade de niveis da água subterrânea na região de Camaçari

O sentido desse movimento é normalmente descendente, provavelmente ainda em conseqüência do intenso bombeamento de água. Esses valores de velocidade, embora biaxos, e o sen- tido descendente do fluxo colocam em risco elevado os recursos hídricos da Formação São Sebastião a partir da contaminação da rede hidrologica superficial, já detectada pela Coordenação de Recursos Ambientais do Estado da Bahia (CRA 1981).

Desse modo, é recomendada a realização de um modelamento hidrogeológico desse sistema objetivando definir um programa de operação otimizado para exploração desse aqüífero, seja quanto à melhor distância entre os poços, seja quanto aos rebaixamentos admissíveis. Além disso, recomenda-se um rigoroso controle de redução da poluição das reservas hídricas superficiais pelos organismos governamentais.

Os resultados geotérmicos indicam a presença de movimentos verticais da água através dos folhelhos. Embora, em geral, os perfis de temperatura mostrem uma uniformidade em profundidade, como conseqüência do intenso bombeamento do aqüífero, alguns poços permitiram calcular velocidades de percolação no intervalo de $8,4 \times 10^{-7} \mathrm{~cm} / \mathrm{s}$ a $1,2 \times 10^{-6} \mathrm{~cm} / \mathrm{s}$.

Agradecimentos Os autores agradecem à Petróleo Brasileiro S.A. (Petrobrás) e à Companhia de Engenharia Rural da Bahia (CERB) pelo forncecimento das cópias' dos perfis elétricos de poços usados neste trabalho. A pesquisa da qual o trabalho faz parte é financiada pela Financiadora de Estudos e Projetos S.A. (Finep) e pelo Conselho Nacional do Desenvolvimento Científico e Tecnológico $(\mathrm{CNPq})$ e reàlizada no âmbito do Programa de Pesquisa e Pós-Graduação em Geofísica da Universidade Federal da Bahia (PPPG/UFBA).

\section{REFERÊNCIAS BIBLIOGRÁFICAS}

ALLEN, D.R. 1975. Identification of sediments - their depositional environment and degree of compactation from well logs. In: CHIL LINGARIAN, G.V. \& WOLF, K.H. eds. Compactation of coarse grained sediments. Elsevier Pub., New York. p. 349-402.

ASMUS, H.E. \& PORTO, R. 1972. Classificação das bacias sedimentares brasileiras segundo a tectônica de placas. In: CONGR. BRAS GEOL., 26, São Paulo, 1972. Anais... São Paulo, SBG, v. 2, p. 67. 90.

BREDEHOEFT, J.D. \& PAPADOPULOS, I.S. 1965. Rates of vertical groundwater movement estimated form the earth's thermal profile. Water Resour. Res., 1:325-328.

BOYLE, J.M. \& SALEEM, Z.A. 1979. Determination of recharge rates using temperature-depth profiles in wells. Water Resour. Res. 15(6): $1616-1622$.

CARVALHO, H.S. \& LOBO, P.F.S. 1985. Pesquisas geotérmicas nas bacias sedimentares da costa leste do Brasil. An. I Sem. de Atualização em Geotermia, Instituto Ítalo-Latino-Americano, p. 259. 267

CRA. 1981. Avaliação e controle de impactos ambientais. Rel. Técnico. Coordenação de Recursos Ambientais, SERPLANTEC, Bahia.

HAMZA, V.M. 1982. Pesquisa de medições de temperatura subsuperficial. Importância para Hidrogeologia. Rev. Agua Subt., 5:65-99.

LEITE, D.C. 1964. Possibilidades de água subterrânea na bacia do Recôncavo Bahiano. PETROBRÁS, Rel. Interno, DEPEX, Salvador.
LIMA, O.A.L. \& RIBEIRO, A.C. 1982. Caracterização hidrogeológica do aquífero São Sebastião na área de captação do CIA/BA, usando perfilagens elétricas de poços, Rev. Bras. Geof., 1(1):11-22.

LIMA, O.A.L. 1983. Filtração de membrana e salinização da água subterrânea - Aplicação a aqüíferos das bacias do Recôncavo e Tucano. Rev. Bras. Geoc., 13(1):23-26.

MILANI, E.J. 1986. Tectônica cisalhante na evolução do rift do Recôncavo-Tucano-Jatobá. Rev. Bras. Geoc., 15(4):287-292.

OLIVEIRA, I.B. \& LIMA, O.A. 1986. Estudo das condições hidrogeológicas e hidroquímicas dos aqüíferos da região de BiritingaPataiba (BA), utilizando métodos geofísicos elétricos. Rev. Bras. Geoc., 16(2): 176-186.

URPLAN. 1985. Abastecimento de água na área industrial do COPEC. Rel. Técnico, Salvador.

VIANA, C.F.; GAMA Jr.; E.G.; SIMÕES, I.A.; MOURA, J.A.; FONSECA, J.R.; ALVES, R.J. 1971. Revisão estratigráfica da bacia do Recôncavo/Tucano. Bol. Tec. Petrobrás, 14(3/4):157-192.

VISHER, G.S. - 1965 - Use of vertical profile in environmental reconstruction. Am. Ass. Petrol. Geol. 49:41-61.

MANUSCRITO 492

Recebido em 02 de setembro de 1987 Revisão aceita em 03 de outubro de 1987 